\title{
BICYCLE USAGE AMONG INACTIVE ADULTS PROVIDED WITH ELECTRICALLY ASSISTED BICYCLES
}

\author{
Stian E. Lobben ${ }^{1}$, Lena Malnes ${ }^{2}$, Sveinung Berntsen ${ }^{2}$, \\ Leif Inge Tjelta ${ }^{3}$, Elling Bere ${ }^{2}$, Morten Kristoffersen ${ }^{4}$, \\ Thomas MildestvedT ${ }^{1}$ \\ ${ }^{1}$ Department of Global Public Health and Primary Care, \\ University of Bergen, Bergen, Norway \\ ${ }^{2}$ Department of Public Health, Sport and Nutrition, University of Agder, \\ Kristiansand, Norway \\ ${ }^{3}$ Department of Education and Sports Science, University of Stavanger, \\ Stavanger, Norway \\ ${ }^{4}$ Department of Sports and Physical Activity, Bergen University College, \\ Bergen, Norway
}

\begin{abstract}
In the present study we aimed primarily to examine cycling time and distance when inactive subjects were provided with electrically assisted bicycles. Secondly to evaluate changes in maximal oxygen uptake. Inactive employees in a selection of public and private corporations in three Norwegian cities were invited to participate. Inclusion criteria were: a desire to cycle to work, residence more than $3 \mathrm{~km}$ from the workplace, and not physically active according to guidelines. There were 25 participants in the study and we provided them all with electrically assisted bicycles fitted with GPS bike computers to record usage. The participants were followed for three to eight months, 226 days on average. Measures of maximal oxygen uptake were performed before and after the intervention. Demographic characteristics and prior transportation habits were reported in a questionnaire at baseline. Participants cycled for $107.1 \pm 62 \mathrm{~min}$ per week covering $37.6 \pm 24 \mathrm{~km}$ per week. The distances cycled were significantly greater in the autumn $(47.4 \mathrm{~km} /$ week, $\mathrm{p}=0.035)$ than in the spring $(32.1 \mathrm{~km} /$ week $)$. Participants cycled more on weekdays $(7.1 \mathrm{~km} / \mathrm{day}$, $\mathrm{p}<0.001)$ compared to weekends $(0.9 \mathrm{~km} /$ day, $\mathrm{p}<0.001)$. Maximal oxygen uptake improved significantly, $2.4 \mathrm{ml} / \mathrm{min} / \mathrm{kg}(7.7 \%), \mathrm{p}<0.001$ and this was associated with cycling distance $(\mathrm{r}=0.49, \mathrm{p}=0.042)$ and self-reported
\end{abstract}


commuting distance $(\mathrm{r}=0.51, \mathrm{p}=0.018)$. Offering electrically assisted bicycles to inactive employees may initiate transport-related physical activity and may give positive health effects.

Keywords: Active commuting, electrically assisted bicycle, maximal oxygen uptake, physical activity promotion

\section{INTRODUCTION}

Physical inactivity is a risk factor comparable to smoking and is a leading cause of premature death in the 21st century [16]. Inactivity is an important cause of coronary heart disease, type 2 diabetes, breast cancer and colon cancer and it caused more than 5.3 million of the 57 million deaths worldwide in 2008. If physical inactivity decreased by $25 \%$, more than 1.3 million deaths could be prevented every year [16]. It is well documented that regular physical activity (PA) has several benefits [20], and a dose-response relationship between PA and all-cause mortality has been reported [24]. Maximal oxygen uptake $\left(\mathrm{VO}_{2 \max }\right)$, the highest rate at which an individual can consume oxygen during exercise, limits the capacity to perform aerobic exercise and is recognized as the best single measure of aerobic fitness [22]. An increase in $\mathrm{VO}_{2 \max }$ of $3.5 \mathrm{ml} / \mathrm{min} / \mathrm{kg}$ is associated with a risk reduction of $13 \%$ for allcause mortality [14]. In addition, $\mathrm{VO}_{2 \max }$ has been estimated to be a better predictor of mortality from cardiovascular disease than other established risk factors such as pack years of smoking, blood pressure, diabetes and cholesterol [1].

In a Norwegian study, only $20 \%$ of adults met the national guidelines for PA of 150 minutes of moderate or 75 minutes of vigorous intensity PA per week [11]. In the U.S. only $10 \%$ of the adult population met the PA guidelines [30]. The effectiveness of interventions to promote and increase PA have been examined, and there is some evidence that public health efforts may successfully increase PA [19]. In a Nordic setting, time constraints and lack of motivation were the two most important reasons to refrain from PA [25]. Active commuting by bike could be an efficient way to incorporate PA into modern lives without requiring extra time and planning and it could have substantial health benefits $[6,8,21,23]$. Adults who use active modes of transportation also reported greater total PA [23]. Increased cycling as a share of overall daily transportation in a population could also have positive effects through decreased air pollution and greenhouse gas emissions [4]. Despite the potential positive health effects of cycling, a minority of the population initiate active commuting by bike. In 2009 cycling contributed 
to $4 \%$ of short-distance journeys conducted in Norway, a reduction from $5 \%$ in 2005 and 7\% in 1992 [17]. Short journeys completed on foot accounted for $22 \%$, and the rest were by car or public transportation. For the three cities in the present study, cycling contributed to $9 \%$ of short-distance journeys in Kristiansand, 5\% in Stavanger, and 3\% in Bergen [17]. Prevalence of commuter cycling varies widely between countries and evidence describing the types of intervention that will increase commuter cycling remains sparse [27]. During the past decade, electrically assisted bicycles (EABs) have become a popular alternative mode of transport [7]. In a Norwegian setting, 66 participants with a mean age of 47 years, were offered an EAB for 9-64 days and followed with a self-reported travel diary. In this study, the number of trips and distance cycled increased compared to a group without access to an EAB. Also, the total share of cycling as a mode of transportation increased in favour of the EAB group [9]. In addition, recent studies illustrated that riding an $\mathrm{EAB}$ may be classified as moderate-to-vigorous intensity PA (MVPA) [2, 26]. One previous study found that commuting by $\mathrm{EAB}$ may increase maximal power output and power output at the anaerobic threshold [3]. However, the intervention lasted for only 6 weeks, and there was no significant improvement in $\mathrm{VO}_{2 \max }$ among the group of untrained white-collar workers who participated. Few studies have examined whether access to an EAB influenced bicycle use and if such activity was associated with improved fitness.

We aimed primarily to examine cycling time and distance when inactive subjects were provided with electrically assisted bicycles. Secondly to evaluate changes in maximal oxygen uptake.

\section{MATERIAL AND METHODS}

\section{Study design}

In the present study, inactive Norwegian adults were given access to an EAB and a bike computer with GPS (Garmin 500). The study was a prospective quasi-experimental intervention. Before the intervention period, participants reported demographic characteristics and prior transportation habits in a questionnaire. Participants recorded cycling frequency and duration using a GPS bike computer. They were provided with an EAB for up to eight months, an extra set of studded tyres for winter use, and the services of a cycle workshop for repairs. Five types of EAB were distributed among the 25 participants. Their assisting electric motor was disabled if the velocity exceeded $25 \mathrm{~km} / \mathrm{h}(15.5 \mathrm{mph})$ or when the participants stopped 
pedalling. This is in accordance with Norwegian legislation and the European Standard. The participants were informed to contact the study leaders by email or phone if they had technical problems with the bikes or the GPS. Participants also performed a cardiorespiratory fitness test, measured as maximal oxygen consumption $\left(\mathrm{VO}_{2 \max }\right)$, pre- and post- intervention.

\section{Study population}

We recruited 25 participants from three Norwegian cities: Bergen, Stavanger and Kristiansand, 23 of them in September 2014 and two in March 2015 due to receipt of additional funding. The intervention period therefore was eight and three months respectively, 226 days on average. Employees in a selection of public and private corporations were invited to participate in the study. Corporations invited employees via intranet, local magazines or by email and then selected participants through convenience sampling. Inclusion criteria were published in the announcement: 1) 18-70 years of age; 2) residence $>3 \mathrm{~km}$ from the workplace; 3 ) a desire to cycle to work most weekdays; and 4) not engaged in regular PA, such as active commuting or endurance training for more than $30 \mathrm{~min}, 2$ days per week. The study leader in each study city, together with a leader from the recruiting company, made a selection of volunteers who met the inclusion criteria and then held an information meeting where the inclusion criteria were clarified and written informed consent was obtained from participants. At this meeting, information about safety in traffic, maintenance of the EABs and user guidance about the GPS device was provided.

In total, 21 participants completed the intervention and performed a post-test. One of 25 included participants withdrew from the study and 3 others did not perform post-test $\mathrm{VO}_{2 \max }$. Reasons were injury (one), moving out of town (one), lost to follow-up (one) and withdrawal (one). Three of the participants did not have valid GPS-measurements (due to technical failure) and additional three others were excluded from the seasonal comparison, one due to GPS-data without a specific date, and two due to the shorter intervention period of three months. The mean age in the group without valid GPS-data was 48 years and two were female. The mean age in the group not eligible for post-testing was 46 years and three were female.

The study was approved by the Regional Committee for Medical Research Ethics, Health Region West (2014/603). Written informed consent was obtained from all participants. 


\section{Measurements}

Participants reported age, gender, education level and commuting distance from home to work in a questionnaire at baseline. Technical issues regarding GPS and EABs were reported in a questionnaire at post-test or by reporting to the study leaders by email.

We recorded bicycle use with GPS (Garmin Edge 500, Southampton, UK) which measured distance, speed, duration and vertical distance. Recorded data were uploaded to Garmin Connect's website (https://connect.garmin. $\mathrm{com} /$ ) by the participants and a member of the research team collected the data at the end of the intervention. Data were manually checked to identify and eliminate user error. Reasons for excluding GPS data from the analyses were: loss of GPS signal during the trip or data with no or minimal movement, for instance if parking the bicycle without turning off the computer.

Pre- and post-tests took place in sports laboratories at the associated universities or colleges in Bergen, Kristiansand, and Stavanger. Direct measures of $\mathrm{VO}_{2 \max }$ were performed on a treadmill using a stepwise modified Balke protocol until exhaustion [5]. The test began with a five-minute warm up with pace at $4.8 \mathrm{~km} / \mathrm{h}$ and followed an increasing workload by incline every two minutes until $20 \%$ incline, at which point speed increased. We measured $\mathrm{VO}_{2 \max }$, minute ventilation (VE) and respiratory exchange ratio (RER) by open-circuit breath-by-breath indirect calorimetry with mixing chamber. Heart rate (HR) was registered every minute with a HR sensor Polar S610i, (Polar Electro, Oy, Kempele, Finland). Time to exhaustion was measured as the number of minutes from test start (including warm up) to maximal exhaustion. We used three types of gas analyzers: Oxycon Pro, (Jaeger GmbH, BeNeLux, Breda, Netherlands) at two of the test centres, and Vmax 29 (Sensor Medics, Yorba Linda, CA, USA) and Vintus CPX (Care Fusion, Hochberg, Germany), at pre- and post-test respectively, at one of the test centres. All gas analysers were calibrated in advance and masks were checked for leakage when clothed. The test leaders verbally encouraged the participants to achieve their maximal capacity during the test. Criteria for acceptable $\mathrm{VO}_{2 \max }$ were the subjective assessment from the test leader that maximum exertion was achieved.

Body weight was measured to the nearest $0.1 \mathrm{~kg}$. Participants selfreported height. 


\section{Statistical analysis}

We used the statistical package SPSS (version 23) for statistical analysis. Descriptive data are reported as mean and standard deviation (SD), numbers and percent in Table I. Results are reported as mean and 95\% confidence intervals (CI) in Table II. Cycling distance recorded with the GPS was transformed using Log10 in order to satisfy normality assumptions. Selfreported commuting distance from home to work was normally distributed. Paired samples t-test was used to compare differences between pre-test and post-test. We analysed the association between variables using Pearson's correlation coefficient.

\section{RESULTS}

The mean age of the 25 participants was 44 years (33-57), and 18 (72\%) were female. Their baseline characteristics are presented in Table 1.

Table 1. Characteristics of study participants at baseline $(n=25)$.

\begin{tabular}{lcc}
\hline Variable & $\mathrm{n}(\%)$ & Mean \pm SD \\
\hline Women & $18(72)$ & \\
\hline Age (years) & & $44 \pm 7$ \\
\hline Height (cm) & $175 \pm 8.6$ \\
\hline Weight (kg) & $82.2 \pm 17.9$ \\
\hline Distance to workplace (km) & $2(8)$ & \\
\hline Part time employed & $20(80)$ & \\
\hline Using car/moped to work & $5(20)$ & \\
\hline Using public transport to work & & \\
\hline Educational level & & \\
\hline High School/Elementary School & $7(28)$ & \\
\hline University/College & $18(72)$ \\
\hline Current smoker & $3(12)$ \\
\hline Married or live in partner, $\mathrm{n}(\%)$ & $22(88)$ \\
\hline
\end{tabular}


Table2. Maximal oxygen consumption $\left(\dot{\mathrm{V}}_{2 \max }\right)$ pre- and post-intervention.

\begin{tabular}{lcccc}
\hline & $\mathrm{N}(\%)$ & Mean $\pm \mathrm{SD}$ & $\begin{array}{l}\text { Observed } \\
\text { min-max }\end{array}$ & $\mathrm{Cl}(95 \%)$ \\
\hline Pretest $\dot{\mathrm{V}} \mathrm{O}_{2 \max }(\mathrm{ml} / \mathrm{min} / \mathrm{kg})$ & $25(100)$ & $33.1 \pm 6.3$ & $20.0-46.9$ & $30.5-35.7$ \\
\hline Posttest $\dot{\mathrm{V}} \mathrm{O}_{2 \max }(\mathrm{ml} / \mathrm{min} / \mathrm{kg})$ & $21(84)$ & $36.5 \pm 4.7$ & $27.2-46.2$ & $34.4-38.6$ \\
\hline
\end{tabular}

GPS data showed that participants spent on average 107.1 \pm 62 minutes cycling, covering $37.6 \pm 24 \mathrm{~km}$ per week during the intervention period. They cycled on average 2 days per week (CI (1.6-2.5)). Distances cycled were significantly $(\mathrm{p}=0.035)$ higher in the autumn $(47.4 \mathrm{~km} /$ week $)$ than in the spring $(32.1 \mathrm{~km} /$ week $)$. There was no significant difference in the distance cycled in the winter season ( $36.4 \mathrm{~km} /$ week) compared to autumn $(\mathrm{p}=0.085)$ or spring $(\mathrm{p}=0.175)$. Participants cycled significantly $(\mathrm{p}<0.001)$ more on weekdays $(7.1 \mathrm{~km} /$ day) compared to weekends $(0.9 \mathrm{~km} /$ day $)$. A decline in cycling activity was observed around holidays when vacation days occurred, in calendar week 52 (Christmas) and calendar week 14 (Easter).

A significant improvement in $\dot{\mathrm{V}}_{2 \max }$ of $2.4 \mathrm{ml} / \mathrm{min} / \mathrm{kg}(7.7 \%), \mathrm{p}<0.001$ from baseline $(34.1 \mathrm{ml} / \mathrm{min} / \mathrm{kg})$ to post-test $(36.5 \mathrm{ml} / \mathrm{min} / \mathrm{kg})$ was associated with GPS-reported weekly cycling distance $(\mathrm{r}=0.49, \mathrm{p}=0.042)$ (Figure 1) and self-reported commuting distance from home to work $(\mathrm{r}=0.51, \mathrm{p}=0.018)$ [Figure 2]. One third of the participants improved their $\dot{\mathrm{V}}_{2 \max } 16 \pm 3.3 \%$.

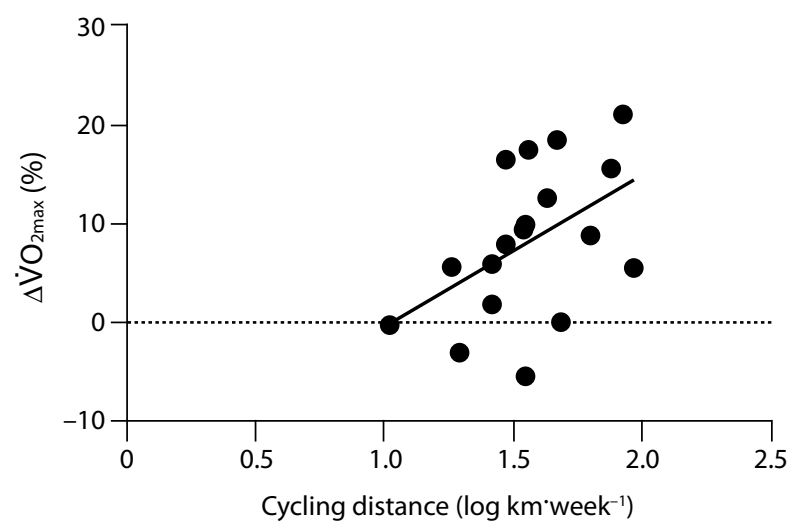

$\mathrm{n}=18 \quad \mathrm{r}=0.49, \mathrm{P}=0.042$

Figure 1. Correlation between $\triangle \mathrm{VO} 2 \mathrm{max} \%$ and GPS-reported cycling distance. 


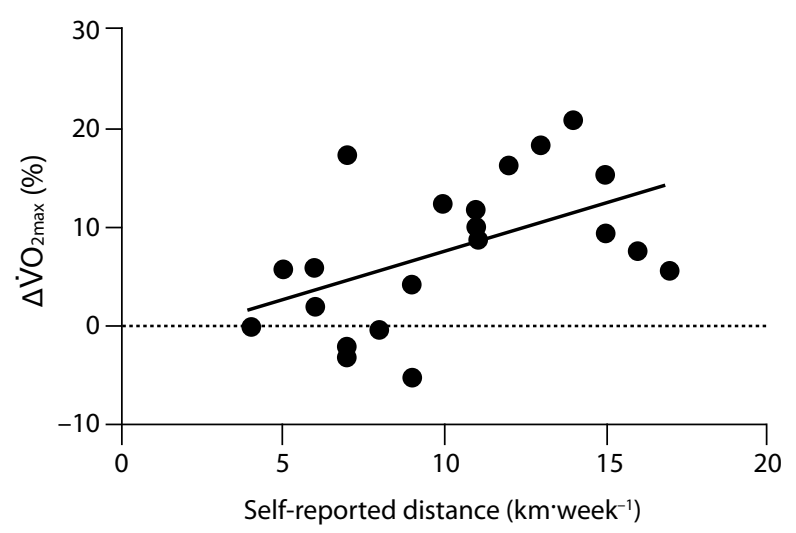

$\mathrm{n}=21 \quad \mathrm{r}=0.51, \mathrm{P}=0.018$

Figure 2. Correlation between $\Delta \mathrm{VO} 2 \mathrm{max} \%$ and self-reported commuting distance.

We found a significant negative correlation $(\mathrm{r}=-0.58, \mathrm{p}<0.01)$ between pre-test $\dot{\mathrm{V}}_{2 \max }$ and absolute improvement in $\mathrm{VO}_{2 \max }$.

The post-testing dropout group reported a mean commuting distance of $21.0 \pm 7.4 \mathrm{~km}$ and they had a mean baseline $\dot{\mathrm{V}}_{2 \max }$ of $27.7 \mathrm{ml} / \mathrm{min} / \mathrm{kg}, 5.3 \mathrm{ml} /$ $\mathrm{min} / \mathrm{kg}$ lower than the average.

\section{DISCUSSION}

This study describes cycling habits and changes in $\mathrm{VO}_{2 \max }$ in 25 selfrecruited, inactive individuals given access to an $\mathrm{EAB}$. The participants used their EABs on average for 107.1 minutes and covered a distance of $37.6 \mathrm{~km}$ per week. They had a significant improvement in $\mathrm{VO}_{2 \max }$, which was associated with commuting distance reported by questionnaire and with weekly cycling distance reported by GPS.

Previous studies have described the effects of providing EABs or regular bicycles on cycling habits and physiological parameters [3, 29]. Studies on the effect of providing participants with an EAB have observed higher selfreported cycled distance, over intervention periods of six weeks and three months, compared to the present study $[3,9]$.

Differences in cycling distance may be influenced by differences in registration method between studies. Self-reported data on active travel has been reported to overestimate compared to GPS data [13]. Objective measure of travel distance is a strength in our study, even though GPS data may be prone to signal loss from satellites and poor adherence of participants to measurement protocols [15]. Four of our participants reported problems 
with registration and uploading data from and this may have led to underestimation of bicycle usage. Cycling distances in previous studies are all based on self-reported data [3,9]. The present intervention period began in September, while the study by Fyhri and Fearnley began in July [9]. Differences in aspects such as geographic, seasonal variance and characteristics of the sample can influence cycled distance with an available EAB. Information provided to participants and follow-up strategy are reported differently between studies. This may also affect differences in reported cycle distance between studies. In our study the participants were encouraged at the baseline meeting to use their $\mathrm{EAB}$ most weekdays, but they were not followed individually in a structured manner in order to stimulate increased bicycle activity.

Adherence to EAB-use was high considering that the intervention took place in late autumn and winter in Norway with mainly cold and wet weather. High adherence to EAB use indicates that this may be a feasible strategy to increase PA among inactive adults. In the present study, we observed a reduction over time in cycled distance, with a significant difference between autumn and spring. A lower adherence in cycling in the winter and spring seasons can only be explained in part by holidays interfering with the daily routine. An alternative explanation could be that participants did not maintain their cycling activity due to lack of motivation over time, which is commonly observed in intervention studies [9]. Both motivation to continue to measure and upload GPS data and motivation to continue cycling as time passed may have influenced the downward trend observed over the eight months of the intervention.

Our study demonstrated improvement in $\mathrm{VO}_{2 \max }$ as opposed to Geus et al. [3] who investigated the physiological effects of commuting by EAB and found increased maximal power output and power output in fixed lactate concentrations on an ergometer but observed no changes in $\mathrm{VO}_{2 \max }$. However, the study by Geus et al. [3] lasted for only six weeks and short duration may have underestimated improvement in $\mathrm{VO}_{2 \max }$ [3, 12]. It is not unexpected that improvements in $\mathrm{VO}_{2 \max }$ in the study by Tjelta et al. [29] which used regular bicycles were greater than in the present study, as exercise intensity is expected to be higher with a regular bicycle than with an $\mathrm{EAB}$ and the participants were encouraged to cycle as much as possible. The participants in the study by Tjelta et al. [29] were tested at the end of summer and cycling dropped during winter. More intensive follow up during the study period and different timing for the tests might explain some of the differences between studies. A negative correlation between pre-test $\mathrm{VO}_{2 \max }$ and improvement in $\mathrm{VO}_{2 \max }$ was seen in the present study. Higher 
intensity PA is more effective in improving $\mathrm{VO}_{2 \max }$ and very fit individuals need greater amounts of activity with vigorous intensity to further improve $\mathrm{VO}_{2 \max }$ [28]. This means that people with higher levels of pre-test $\mathrm{VO}_{2 \max }$ may need to choose cycling activity with a more vigorous intensity than the participants with lower pre-test $\mathrm{VO}_{2 \max }$ in order to achieve improvements in $\mathrm{VO}_{2 \max }$. We observed an improvement of $2.4 \mathrm{ml} / \mathrm{min} / \mathrm{kg}(7.7 \%)$ in $\mathrm{VO}_{2 \max }$ and although this may appear small, findings from a meta-analysis indicate that even $1 \mathrm{MET}, 3.5 \mathrm{ml} / \mathrm{min} / \mathrm{kg}$ increase in $\mathrm{VO}_{2 \max }$ is associated with a risk reduction of $13 \%$ for mortality and of $15 \%$ for cardiovascular diseases [14].

\section{Strengths and limitations}

A strength of the present study is the quality of the measurements with objective assessments of bicycle use with a GPS computer and direct measurements of $\mathrm{VO}_{2 \max }$. We included participants from three different cities with variations in bike infrastructure, topography and weather conditions. Most participants were followed for eight months including several seasons; autumn, winter and spring. The participants represented a heterogenic group concerning age, gender, workplace and travel distance. Feasible inclusion and recruitment procedures also supported the external validity of our findings. However, our results must be interpreted with caution with respect to the study's limitations. We included a self-recruited group motivated to change to $\mathrm{EAB}$ as a preferred mode of transportation to work and our findings may not be valid for the whole population of physically inactive workers. Even though we did not have protocol-guided contact with the participants during the study period we still had contact with most participants in order to solve any technical problems and to initiate technical services. Taking part in a study and having interactions with the researchers may have influenced participants' motivation to use their EABs [18]. Lack of GPS data from some participants gives us reason to believe that measured travel time and distance could be underestimated. Other reported technical issues such as battery capacity, participant adherence and signal loss should also be taken into consideration. VO2max-testing in nine participants at one study centre was conducted with a different device compared to baseline. A reliability analysis on two test persons tested at four submaximal power outputs showed $7 \%$ higher $\mathrm{VO} 2$-values using the Vyntus-O2-analyzer as used during post measures (Bentsen S 2017, unpublished data).

This pilot study had a small sample size and no control group, therefore we can only examine associations. No causal relationships regarding the effect of EAB use can be drawn. Even though our findings suggest a clini- 
cally relevant increase of $\mathrm{VO}_{2 \max }$, participants did not report other changes in PA level that may have contributed to the improvements in $\mathrm{VO}_{2 \max }$ [30]. Familiarisation of the test procedure at baseline might also have contributed to an increase of $\mathrm{VO}_{2 \max }$ at post-test. Four participants were not eligible for post-testing. However, pre-test $\mathrm{VO}_{2 \max }$ among these participants was relatively low, but not significantly different from the rest of the group.

\section{Conclusions}

The present study suggests that giving access to EABs mobilize inactive individuals to initiate transport-related PA. We need additional studies to evaluate the influence on cardiorespiratory fitness.

\section{Implications for practice and further research}

To the authors' knowledge this is the first study to objectively evaluate cycled distance when participants are given access to an $\mathrm{EAB}$, and the association between cycled distances and changes in $\mathrm{VO}_{2 \max }$ over an extended period. These findings might be considered as exploratory and may function as a knowledge base for further research, preferably with a larger samples size and using a randomised controlled design including EAB, regular bicycles and a control group. Further studies should also include long term follow-up in order to describe maintenance of PA after an intervention. Our results can be used for calculations of statistical power.

To avoid missing data it is important to keep procedures for registration and reporting of PA easy and accessible. Technology is rapidly progressing and applications for smartphones opens for cost-efficient registration of PA, including registration of physiological parameters.

\section{ACKNOWLEDGEMENTS}

Funding: The GC Rieber Funds; Bergen Council; Stavanger University Hospital; Kristiansand Zoo and Amusement park; National Oilwell Varco Norway AS; General Practitioner-scholarship from the Norwegian Medical Association. 


\section{REFERENCES}

1. Blair SN, Kohl HW, 3rd, Paffenbarger RS, Jr., Clark DG, Cooper KH, Gibbons LW. (1989) Physical fitness and all-cause mortality. A prospective study of healthy men and women. JAMA, 262(17):2395-2401.

2. Boris G, Joris W, Katia I, Chantal D, Gerald G. (2011) Electric bikes as a new active transportation modality to promote health. Med Sci Sports Exerc, 43(11): 2204-2210.

3. de Geus B, Kempenaers F, Lataire P, Meeusen R. (2013) Influence of electrically assisted cycling on physiological parameters in untrained subjects. Eur J Sport Sci, 13(3): 290-294.

4. de Hartog JJ, Boogaard H, Nijland H, Hoek G. (2010) Do the health benefits of cycling outweigh the risks? Environ Health Perspect, 118(8): 1109-1116.

5. Edvardsen E, Hem E, Anderssen SA. (2014) End criteria for reaching maximal oxygen uptake must be strict and adjusted to sex and age: a cross-sectional study. PLoS One, 9(1): e85276.

6. Ekblom-Bak E, Ekblom B, Vikstrom M, de Faire U, Hellenius ML. (2014) The importance of non-exercise physical activity for cardiovascular health and longevity. Br J Sports Med, 48(3): 233-238.

7. Fishman E, Cherry C. (2015) E-bikes in the Mainstream: Reviewing a Decade of Research. Transport Reviews, 1-20.

8. Foley L, Panter J, Heinen E, Prins R, Ogilvie D. (2015) Changes in active commuting and changes in physical activity in adults: a cohort study. Int J Behav Nutr Phys Act, 12(1): 161.

9. Fyhri A, Fearnley N. (2015) Effects of e-bikes on bicycle use and mode share. Transportation Research Part D: Transport and Environment, 36: 45-52.

10. Gomersall S, Maher C, English C, Rowlands A, Olds T. (2015) Time regained: when people stop a physical activity program, how does their time use change? A randomised controlled trial. PLoS One, 10(5): e0126665.

11. Hansen BH, Kolle E, Dyrstad SM, Holme I, Anderssen SA. (2012) Accelerometer-determined physical activity in adults and older people. Med Sci Sports Exerc, 44(2): 266-272.

12. Hickson RC, Bomze HA, Holloszy JO. (1977) Linear increase in aerobic power induced by a strenuous program of endurance exercise. J Appl Physiol Respir Environ Exerc Physiol, 42(3): 372-376.

13. Kelly P, Krenn P, Titze S, Stopher P, Foster C. (2013) Quantifying the difference between self-reported and global positioning systems-measured journey durations: A systematic review. Transport Reviews, 33(4): 443-459.

14. Kodama S, Saito K, Tanaka S, Maki M, Yachi Y, Asumi M, Sugawara A, Totsuka K, Shimano H, Ohashi Y, Yamada N, Sone H. (2009) Cardiorespiratory fitness as a quantitative predictor of all-cause mortality and cardiovascular events in healthy men and women: A meta-analysis. JAMA, 301(19): 2024-2035. 
15. Krenn PJ, Titze S, Oja P, Jones A, Ogilvie D. (2011) Use of global positioning systems to study physical activity and the environment: a systematic review. Am J Prev Med, 41(5): 508-515.

16. Lee IM, Shiroma EJ, Lobelo F, Puska P, Blair SN, Katzmarzyk PT. (2012) Effect of physical inactivity on major non-communicable diseases worldwide: an analysis of burden of disease and life expectancy. Lancet, 380(9838): 219-229.

17. Vågane L, Brechan I, Hjorthol R. Den nasjonale reisevaneundersøkelsen 2009 nøkkelrapport [2009 Norwegian Travel Survey] 2009 1130/2011 Contract No.: 978-82-480-1194-1.

18. McCambridge J, Witton J, Elbourne DR. (2014) Systematic review of the Hawthorne effect: new concepts are needed to study research participation effects. J Clin Epidemiol, 67(3): 267-277.

19. Muller-Riemenschneider F, Reinhold T, Nocon M, Willich SN. (2008) Long-term effectiveness of interventions promoting physical activity: a systematic review. Prev Med, 47(4): 354-368.

20. Oja P, Bull FC, Fogelholm M, Martin BW. (2010) Physical activity recommendations for health: what should Europe do? BMC Public Health, 10: 10.

21. Oja P, Titze S, Bauman A, de Geus B, Krenn P, Reger-Nash B, Kohlberger T. (2011) Health benefits of cycling: a systematic review. Scand J Med Sci Sports, 21(4): 496-509.

22. Pescatello LS, Arena R, Riebe D, Thompson PD. (2014) ACSM's guidelines for exercise testing and prescription. 9th ed. ed. Philadelphia, Pa: Wolters Kluwer Health/Lippincott Williams \& Wilkins.

23. Sahlqvist S, Song Y, Ogilvie D. (2012) Is active travel associated with greater physical activity? The contribution of commuting and non-commuting active travel to total physical activity in adults. Prev Med, 55(3): 206-211.

24. Samitz G, Egger M, Zwahlen M. (2011) Domains of physical activity and allcause mortality: systematic review and dose-response meta-analysis of cohort studies. Int J Epidemiol, 40(5): 13821-400.

25. Anderssen SA, Hansen BH, Kolle E, Steene-Johannessen J, Børsheim E, Holme I, Kan1-gruppen. Fysisk aktivitet blant voksne og eldre i Norge - Resultater fra en kartlegging i 2008/2009. [Physical activity among adults and the elderly in Norway. Results from a survey in 2008 and 2009.] (In Norwegian). https://helsedirektoratet.no/publikasjoner/fysisk-aktivitet-blant-voksne-og-eldre-resultaterfra-en-kartlegging-i-2008-og-2009: Norwegian Directorate of Health, 2009 ISBN 978-82-8081-187-5.

26. Sperlich B, Zinner C, Hebert-Losier K, Born DP, Holmberg HC. (2012) Biomechanical, cardiorespiratory, metabolic and perceived responses to electrically assisted cycling. Eur J Appl Physiol, 112(12): 4015-4025.

27. Stewart G, Anokye NK, Pokhrel S. (2015) What interventions increase commuter cycling? A systematic review. BMJ Open, 5(8): e007945.

28. Swain DP. (2005) Moderate or vigorous intensity exercise: which is better for improving aerobic fitness? Prev Cardiol, 8(1): 55-58. 
29. Tjelta LI, Kvåle OH, Dyrstad SM. (2010) Helsegevinst ved sykling til jobb. [Health effects of cycling to and from work]. Tidsskr Nor Laegeforen, 130(12): 1246-1249.

30. Tucker JM, Welk GJ, Beyler NK. (2011) Physical activity in U.S.: adults compliance with the Physical Activity Guidelines for Americans. Am J Prev Med, 40(4): 454-461.

\section{Correspondence to:}

Thomas Mildestvedt

Department of Global Public Health and Primary Care

University of Bergen, Bergen, Norway.

Phone: +47 55586163

Email: thomas.mildestvedt@uib.no 